\title{
Trends of dental caries in permanent teeth among 12-year-old Chinese children: evidence from five consecutive national surveys between 1995 and 2014
}

\author{
Zhen $\mathrm{Hu}^{1,2+}$, Xiaojin Yan ${ }^{1,3+}{ }^{\text {, Yi Song }}{ }^{1}$, Shang $\mathrm{Ma}^{4}$, Jun Ma ${ }^{1}$ and Guangrong Zhu ${ }^{1 *}$
}

\begin{abstract}
Background: Dental caries have a serious impact on general health and well-being; however, there is a lack of relevant data on the development trends of dental caries in permanent teeth among 12-year-old children in China. We aim to assess long-term trends of dental caries in permanent teeth among 12-year-old children in China and identify the susceptible subgroups based on five consecutive national surveys from 1995 to 2014.

Methods: A total of 88972 subjects were extracted from five consecutive national surveys (1995, 2000, 2005, 2010, 2014). Standardized dental examinations were conducted and the oral health status of each subject was recorded. The prevalence of Decayed, Missing and Filled teeth (DMF\%), mean Decayed, Missing, Filled teeth score (DMFT) and Caries Filling Ratio (CFR) were used as measurement indicators. Cochran-Armitage trend test was used to evaluate the trends in DMF\% and CFR, and multivariate linear regression was used to evaluate the trends in DMFT.

Results: A V-shaped fluctuating upward trend in DMF\% during 1995-2014 was observed $(Z=-13.124, P<0.001)$, and the DMF\% in 1995-2014 was $21.1 \%, 15.9 \%, 16.2 \%, 21.9 \%$ and $24.3 \%$. The trend in DMFT was approximately consistent with DMF\% $(\beta=0.057, P<0.001)$, but the downward volatility appeared in 2014 . The DMFT in 1995-2014 was $0.38,0.28,0.31,0.66$ and 0.54 . A continuously fluctuant trend in CFR was observed during past two decades $(Z=1.927$, $P>0.05)$, and the CFR in 1995-2014 was 17.4\%, 22.8\%, 19.3\%, 23.4\% and 15.6\%. The DMF\% and DMFT of rural children had a larger absolute increase than that of urban children during 1995-2014 (DMF\%-urban: $Z=-0.242, P>0.05$; DMF\%-rural: $Z=-19.036, P<0.001$; DMFT-urban: $\beta=0.035, P<0.001$, DMFT-rural: $\beta=0.077, P<0.001)$. The DMF\% and DMFT in girls were higher than that in boys at each survey year $(P<0.001)$. CFR of urban children was higher than that of rural children at each survey year $(P<0.001)$.
\end{abstract}

Conclusions: Over the past 20 years, DMFT and DMF\% of 12-year-old children in China presented V-shaped fluctuant upward trends, with a decline trend from 1995 to 2000 and an upward trend from 2000 to 2014. CFR had no significant improvement. The rural children and girls are the more vulnerable groups in the development of dental caries and need to pay priority. Our study supports the continuation of policies to improve children' oral health.

Keywords: Permanent teeth, Prevalence, DMFT, Caries filling ratio, Children, China

*Correspondence: zhuguangrong@bjmu.edu.cn

tZhen Hu and Xiaojin Yan have contributed equally to this article

${ }^{1}$ Institute of Child and Adolescent Health, School of Public Health, Peking

University, No. 38 Xueyuan Rd, Haidian District, Beijing 100191, China

Full list of author information is available at the end of the article

\section{Background}

Dental caries are a major public health problem as one of the most widespread non-communicable diseases (NCD) worldwide [1]. Together with tumor and 
hypertension, dental caries are listed by the World Health Organization (WHO) as the three major noncommunicable diseases that need to be mainly prevented and treated [2]. Everyone is at risk of dental caries, while children have the highest. WHO recommended the age of 12 as the target age for global dental caries detection and the prevalence of Decayed, Missing and Filled teeth (DMF\%), mean Decayed, Missing, Filled teeth score (DMFT) and Caries Filling Ratio (CFR) as the measurement indicators of dental caries in permanent teeth [3]. Globally, the data of 1995-1996 showed that DMFT of Chinese children aged 12 was $1.0 \sim 0.9$, which was at a very low level [4]. However, the trend of dental caries generally emerged a relatively fluctuating trend and was inconsistent in various countries [5]. A previous Chinese study reported a trend of permanent dental caries in 12-year-olds from 1991 to 2005 [6]. However, the data they use was old and outdated so that it needs to be updated urgently.

Numerous studies have shown that dental caries had different distributions across areas and gender. Urban-rural differences in dental caries exist but with controversial findings, for example, one survey from North-Eastern Italy indicated that the prevalence of decay is lower in an urban context among schoolchildren [7]. Another survey conducted in India manifested that children had a higher risk of dental caries if they lived in urban area [8]. So did the gender disparities in dental caries. In Guwahati city, the boys exhibited higher caries prevalence than the girls [9], while girls were at higher risk than boys in Indonesia [10]. However, vulnerable population of children with dental caries in China has been less researched.

Previous studies demonstrated that during the past two decades, Chinese children have experienced a rapid lifestyle transition [11], per capita output of sugar crops dramatically increased from $65.90 \mathrm{~kg}$ in 1995 to $88.61 \mathrm{~kg}$ in 2014 [12]. The consumption proportion of sugar-containing food in girls was higher than that of boys [13]. However, few representative data is available to estimate the national trends of dental caries in permanent teeth of 12-year-old Chinese children or identify the susceptible subgroups. Therefore, the nationally representative Chinese National Survey on Students' Constitution and Health $(\mathrm{CNSSCH})$ provided a unique opportunity for us to fill the gaps. In this study, we aim to assess national trends of dental caries in permanent teeth among 12-year-old Chinese children and identify the susceptible subgroups based on five consecutive national surveys between 1995 and 2014.

\section{Methods}

This study was approved by the Medical Research Ethics Committee of the Peking University Health Science Center (IRB00001052-18002). Informed consent was obtained verbally because written consent was difficult to obtain in the national surveys.

\section{Study design}

Consecutive cross-sectional studies were respectively conducted in 1995, 2000, 2005, 2010 and 2014 in China.

\section{Setting}

The CNSSCH is a national survey, which has been conducted every five years since 1985, jointly launched by the Ministry of Education, the Ministry of Health, the Ministry of Science and Technology, the State of Nation Affairs, and the State Sports General Administration of People's Republic of China. The objective of the CNSSCH studies is to grasp the Chinese students' constitution and health status and development trend, promote local and school to fully implement the Party's education policy in the new era, and scientifically evaluate the efficiencies of school physical education, hygiene and health education. It provides the basis for making the development plan and scientifically carrying out the work of school physical education, hygiene and health education. The test items include 24 indicators from 4 aspects, including body shape, physiological function, physical fitness and health status. Our report used the data of caries in 12-yearold children from the $\mathrm{CNSSCH}$ study. The $\mathrm{CNSSCH}$ used a multistage stratified cluster sampling design and has maintained consistent approaches to sampling and assessment across the different survey years, as previously described [14-16]. Briefly, all the subjects were primary and high school students aged 7-18 years randomly selected from 30 of the 31 mainland provinces, excluding Tibet. In each province, survey sites and schools were randomly selected from three socioeconomic slices ("upper", "moderate" and "low"). In each survey school, the class was taken as the unit for random cluster sampling, stratified by grade. The number of classes selected should meet the minimum sample size. It was determined that sample sizes could be reduced without greatly sacrificing the survey's statistical analyses power. The subjects were divided into four categories: urban, rural, male and female, with a minimum sample size of 50 people for each section, each category and each age group.

\section{Participants and study size}

Between 1995 and 2014, 1084649 children and adolescents aged 7-18 years participated in the $\mathrm{CNSSCH}$, of 
those, 88972 participants aged 12 were included in our study as the analysis sample.

\section{Data sources/measurement}

A total of 60 to 150 oral professionals were involved in the clinical examination process at each survey year, all of them were required to pass a training course for the investigation. They performed oral examinations in sufficient lighting using a surface reflection mirror and a No.5 explorer in 1995 and 2000 survey year, with disposable oral instrument box replaced since 2005. Standardized dental examinations were conducted in a uniform sequence and Decayed, Missing and Filled teeth condition of permanent teeth were recorded. Thirty mainland provinces were analysed in our study, and they were divided into three regions: the east region, the central region and the west region according to the geographical standard division from the National Bureau of Statistics of China [17].

Diagnostic criteria for dental caries were as following $[18,19]$ :

The lesion in fissure or the smooth surface of the tooth has a soft base, with underlying damaged enamel or wall softening, also including temporary fillings (such as zinc oxide) in the teeth. Caries include fissure caries and smooth surface caries (teeth with caries on the adjacent, buccal and lingual surfaces).

'Decayed tooth' (DT) designates a tooth in which a cavity could clearly be seen or a lesion could be felt with an explorer in a pit or fissure, or on a smooth surface.

'Missing tooth' (MT) designates a tooth that had been lost or extracted for dental caries not at replacement age. Third molars were excluded.

'Filled tooth' (FT) designates a tooth with one or more permanent restorations and no cavity anywhere on the tooth.

\section{Variables}

(1) DMF\%: the percentage (\%) of the persons who had decayed, missing and filled in permanent teeth among all participants examined. When calculating, the total numbers of persons who had decayed, missing, filled in permanent teeth were used as the numerator, and the number of all participants examined were used as the denominator, which was expressed as a percentage (\%).

(2) DMFT: the mean number of caries $(D+M+F)$ among all participants examined. When calculating, the total teeth numbers of decayed, missing and filled in permanent teeth were used as the numerator, and the number of all participants examined were used as the denominator, which was expressed as mean \pm standard deviation $(-\mathrm{X} \pm \mathrm{S})$.
(3) CFR: the ratio of the total teeth number of filling to the total teeth number of decayed, missing and filled in permanent teeth among all participants examined. When calculating, the total teeth numbers of filling in permanent teeth were used as the numerator, and the total teeth numbers of decayed, missing and filled in permanent teeth were used as the denominator, which was expressed as a percentage (\%).

\section{Bias}

The $\mathrm{CNSSCH}$ has maintained consistent approaches to sampling and assessment across the different survey years. Participants with missing data or biologically implausible values were excluded from the study. Dental caries measurements and diagnosis in the CNSSCH followed a standardized procedure and were conducted by trained and qualified oral professionals. The principles underlying the methods and instruments were the same at each survey site.

\section{Statistical methods}

Categorical variables were characterized by frequencies and percentages, and continuous variables were characterized as mean \pm standard deviation. Chi-square test was used to compare the gender differences of DMF\% and CFR in overall and subgroups of each survey year, and $t$-test was used to compare the gender differences of DMFT in overall and subgroups of each survey year. In addition, Cochran-Armitage trend test was utilized to evaluate the trends of DMF\% and CFR in overall and subgroups, and Multivariate linear regression was utilized to evaluate the trends of DMFT in overall and subgroups. Two-sided $P<0.05$ was considered to be statistically significant. All statistical analyses were conducted with $R$ version 4.0.2 software ( $\mathrm{R}$ Foundation for Statistical Computing, Vienna, Austria) and SPSS, version 20.0 (IBM, Armonk, New York).

\section{Results}

\section{Participants and descriptive data}

The study sample consisted of 88,772 children, with $17,305,17,609,18,213,17,852$ and 17,793 participants from 1995 to 2000, respectively. The distribution of participants by area (rural 50.8\%) and gender (girls 50.0\%) was basically balanced. The demographic characteristics of the participants are provided in Table 1.

\section{Outcome data \\ The trend of DMF\% in overall and subgroups}

Nationwide, we observed a $\mathrm{V}$-shaped fluctuating upward trend in DMF\% during 1995-2014 period $(\mathrm{Z}=-13.124$, $P<0.001$ ), and the DMF\% decreased from $21.1 \%$ in 1995 to $15.9 \%$ in 2000 , and then consistently increased from 
Table 1 Demographic characteristics of the participants

\begin{tabular}{|c|c|c|c|}
\hline & Boys & Girls & Total \\
\hline Overall & $44,404(50.0)$ & $44,368(50.0)$ & $88,772(100)$ \\
\hline \multicolumn{4}{|l|}{1995} \\
\hline Total & $8720(50.4)$ & 8585 (49.6) & $17,305(100.0)$ \\
\hline \multicolumn{4}{|l|}{ Area } \\
\hline Urban & 4393 (50.0) & $4393(50.0)$ & 8786 (50.8) \\
\hline Rural & 4327 (50.8) & $4192(49.2)$ & $8519(49.2)$ \\
\hline \multicolumn{4}{|l|}{ Region } \\
\hline East & 3385 (50.0) & $3382(50.0)$ & $6767(39.1)$ \\
\hline Central & $2537(50.0)$ & $2537(50.0)$ & $5074(29.3)$ \\
\hline West & $2798(51.2)$ & $2666(48.8)$ & $5464(31.6)$ \\
\hline \multicolumn{4}{|l|}{2000} \\
\hline Total & 8748 (49.7) & $8861(50.3)$ & $17,609(100.0)$ \\
\hline \multicolumn{4}{|l|}{ Area } \\
\hline Urban & 4414 (49.8) & $4446(50.2)$ & $8860(50.3)$ \\
\hline Rural & 4334 (49.5) & $4415(50.5)$ & $8749(49.7)$ \\
\hline \multicolumn{4}{|l|}{ Region } \\
\hline East & 3614 (48.9) & $3783(51.1)$ & $7397(42.0)$ \\
\hline Central & 2281 (49.8) & $2297(50.2)$ & $4578(26.0)$ \\
\hline West & 2853 (50.6) & $2781(49.4)$ & $5634(32.0)$ \\
\hline \multicolumn{4}{|l|}{2005} \\
\hline Total & $9121(50.1)$ & 9092 (49.9) & $18,213(100.0)$ \\
\hline \multicolumn{4}{|l|}{ Area } \\
\hline Urban & $4573(50.1)$ & 4549 (49.9) & $9122(50.1)$ \\
\hline Rural & $4548(50.0)$ & $4543(50.0)$ & 9091 (49.9) \\
\hline \multicolumn{4}{|l|}{ Region } \\
\hline East & 3517 (50.7) & $3416(49.3)$ & $6933(38.1)$ \\
\hline Central & $2190(49.1)$ & $2272(50.9)$ & $4462(24.5)$ \\
\hline West & 3414 (50.1) & 3404 (49.9) & $6818(37.4)$ \\
\hline \multicolumn{4}{|l|}{2010} \\
\hline Total & 8913 (49.9) & $8939(50.1)$ & $17,852(100.0)$ \\
\hline \multicolumn{4}{|l|}{ Area } \\
\hline Urban & 4452 (49.9) & $4473(50.1)$ & $8925(50.0)$ \\
\hline Rural & $4461(50.0)$ & $4466(50.0)$ & $8927(50.0)$ \\
\hline \multicolumn{4}{|l|}{ Region } \\
\hline East & $3266(50.0)$ & $3272(50.0)$ & 6538 (36.6) \\
\hline Central & 2361 (49.9) & $2373(50.1)$ & $4734(26.5)$ \\
\hline West & 3286 (49.9) & $3294(50.1)$ & $6580(36.9)$ \\
\hline \multicolumn{4}{|l|}{2014} \\
\hline Total & 8902 (50.0) & $8891(50.0)$ & $17,793(100.0)$ \\
\hline \multicolumn{4}{|l|}{ Area } \\
\hline Urban & $4453(50.0)$ & $4445(50.0)$ & $8898(50.0)$ \\
\hline Rural & 4449 (50.0) & $4446(50.0)$ & $8895(50.0)$ \\
\hline \multicolumn{4}{|l|}{ Region } \\
\hline East & $3282(49.9)$ & $3294(50.1)$ & $6576(37.0)$ \\
\hline Central & $2393(50.0)$ & $2390(50.0)$ & $4783(26.9)$ \\
\hline West & 3227 (50.2) & 3207 (49.8) & $6434(36.2)$ \\
\hline
\end{tabular}

Table 2 DMF\% in 12-year-old Chinese children by gender (\%, $95 \% \mathrm{Cl})$

\begin{tabular}{|c|c|c|c|c|}
\hline & Overall & Boys & Girls & $\begin{array}{l}\text { Chi-square- } \\
\text { test } P \text { value }\end{array}$ \\
\hline \multicolumn{5}{|l|}{1995} \\
\hline Total & $21.1(20.5-21.7)$ & $18.9(18.1-19.7)$ & $23.4(22.5-24.3)$ & $<0.001$ \\
\hline \multicolumn{5}{|l|}{ Area } \\
\hline Urban & $26.0(25.0-26.9)$ & $22.9(21.7-24.1)$ & $29.0(27.7-30.4)$ & $<0.001$ \\
\hline Rural & $16.1(15.3-16.9)$ & $14.8(13.8-15.9)$ & 17.5 (16.3-18.6) & $<0.001$ \\
\hline \multicolumn{5}{|l|}{ Region } \\
\hline East & $27.4(26.3-28.5)$ & $24.0(22.5-25.4)$ & $30.8(29.3-32.4)$ & $<0.001$ \\
\hline Central & $17.3(16.2-18.3)$ & $14.8(13.4-16.2)$ & $19.7(18.2-21.3)$ & $<0.001$ \\
\hline West & 16.9 (15.9-17.9) & $16.5(15.1-17.9)$ & $17.4(16.0-18.8)$ & 0.360 \\
\hline \multicolumn{5}{|l|}{2000} \\
\hline Total & $15.9(15.3-16.4)$ & $14.0(13.3-14.8)$ & 17.7 (16.9-18.5) & $<0.001$ \\
\hline \multicolumn{5}{|l|}{ Area } \\
\hline Urban & $18.0(17.2-18.8)$ & $16.4(15.3-17.5)$ & 19.5 (18.3-20.7) & $<0.001$ \\
\hline Rural & $13.8(13.0-14.5)$ & $11.6(10.7-12.6)$ & $15.8(14.8-16.9)$ & $<0.001$ \\
\hline \multicolumn{5}{|l|}{ Region } \\
\hline East & $22.7(21.8-23.7)$ & $20.1(18.8-21.4)$ & 25.3 (23.9-26.6) & $<0.001$ \\
\hline Central & $9.7(8.8-10.5)$ & $9.1(7.9-10.3)$ & $10.2(9.0-11.5)$ & 0.187 \\
\hline West & $12.0(11.1-12.8)$ & $10.4(9.3-11.5)$ & $13.6(12.3-14.8)$ & $<0.001$ \\
\hline \multicolumn{5}{|l|}{2005} \\
\hline Total & $16.2(15.7-16.8)$ & $13.9(13.2-14.6)$ & 18.6 (17.8-19.4) & $<0.001$ \\
\hline \multicolumn{5}{|l|}{ Area } \\
\hline Urban & $16.8(16.1-17.6)$ & $14.2(13.2-15.2)$ & 19.5 (18.3-20.6) & $<0.001$ \\
\hline Rural & 15.7 (14.9-16.4) & $13.6(12.6-14.6)$ & $17.8(16.7-18.9)$ & $<0.001$ \\
\hline \multicolumn{5}{|l|}{ Region } \\
\hline East & $20.0(19.0-20.9)$ & $16.5(15.3-17.7)$ & $23.6(22.1-25.0)$ & $<0.001$ \\
\hline Central & $13.9(12.9-14.9)$ & $12.7(11.3-14.1)$ & $15.0(13.5-16.4)$ & 0.032 \\
\hline West & $14.0(13.2-14.8)$ & $11.9(10.8-13.0)$ & $16.1(14.9-17.3)$ & $<0.001$ \\
\hline \multicolumn{5}{|l|}{2010} \\
\hline Total & $21.9(21.3-22.5)$ & $19.2(18.4-20.0)$ & $24.6(23.7-25.5)$ & $<0.001$ \\
\hline \multicolumn{5}{|l|}{ Area } \\
\hline Urban & $22.5(21.7-23.4)$ & $19.8(18.6-21.0)$ & $25.3(24.0-26.5)$ & $<0.001$ \\
\hline Rural & $21.3(20.4-22.1)$ & 18.7 (17.5-19.8) & $23.9(22.6-25.1)$ & $<0.001$ \\
\hline \multicolumn{5}{|l|}{ Region } \\
\hline East & $20.4(19.4-21.4)$ & $16.5(15.2-17.8)$ & $24.3(22.8-25.8)$ & $<0.001$ \\
\hline Central & 20.7 (19.6-21.9) & $18.7(17.1-20.3)$ & $22.7(21.0-24.4)$ & $<0.001$ \\
\hline West & $24.2(23.2-25.3)$ & $22.3(20.9-23.7)$ & $26.2(24.7-27.7)$ & $<0.001$ \\
\hline \multicolumn{5}{|l|}{2014} \\
\hline Total & $24.3(23.6-24.9)$ & $20.3(19.5-21.2)$ & $28.2(27.3-29.1)$ & $<0.001$ \\
\hline \multicolumn{5}{|l|}{ Area } \\
\hline Urban & $23.8(22.9-24.7)$ & 19.7 (18.6-20.9) & $27.9(26.5-29.2)$ & $<0.001$ \\
\hline Rural & $24.7(23.8-25.6)$ & $20.9(19.8-22.1)$ & $28.5(27.2-29.9)$ & $<0.001$ \\
\hline \multicolumn{5}{|l|}{ Region } \\
\hline East & $28.6(27.5-29.7)$ & $24.0(22.5-25.4)$ & $33.2(31.6-34.8)$ & $<0.001$ \\
\hline Central & $21.4(20.2-22.6)$ & $17.8(16.2-19.3)$ & $25.1(23.3-26.8)$ & $<0.001$ \\
\hline West & $22.0(20.9-23.0)$ & $18.6(17.2-19.9)$ & $25.4(23.9-26.9)$ & $<0.001$ \\
\hline
\end{tabular}


$16.2 \%$ in 2005 to $24.3 \%$ in 2014 (Table 2, Additional file 1: Table 1). The DT\% in 1995-2014 was $17.9 \%, 12.7 \%$, $13.4 \%, 18.4 \%$ and $20.4 \%$, the MT\% was $0.7 \%, 0.6 \%, 0.6 \%$, $3.2 \%$ and $1.2 \%$, the FT\% was $4.1 \%, 3.9 \%, 3.3 \%, 5.8 \%$ and 4.6\% (Fig. 1, Additional file 2: Table 2). When further stratified by DT\%, MT\% and FT\%, the trends of DT\% showed similar pattern with the total sample. During 1995-2014, DMF\% of rural children had a dramatically larger absolute increase than that of urban counterparts (urban: $Z=-0.242, P>0.05$; rural: $Z=-19.036$, $P<0.001)$. In 2014, DMF\% of rural children $(24.7 \%)$ even exceeded that of their urban peers (23.8\%). Meanwhile, DMF\% of girls were higher than that of boys in all survey years and almost all subgroups $(P<0.001)$. Except in 2010 , the DMF\% in the east was higher than that in the west and central regions $(P<0.001)$ (Table 2 , Additional file 1: Table 1).

\section{The trend of DMFT in overall and subgroups}

A fluctuant upward trend of the DMFT was discovered during 1995-2014 $(\beta=0.057, P<0.001)$, with a decrease from 0.38 in 1995 to 0.28 in 2000 and an increase to 0.66 in 2010, then a fell to 0.54 in 2014. Trend in DMFT was generally consistent with that in DMF\%. However, the downward volatility appeared in 2014 (Table 3, Additional file 1: Table 1). The DT in $1995-2014$ was 0.31 , $0.21,0.24,0.40$ and 0.43 , the MT was $0.01,0.01,0.01$, 0.11 and 0.03 , the FT was $0.07,0.06,0.06,0.15$ and 0.08 (Fig. 2, Additional file 2: Table 2). During 1995-2014, DMFT of rural children had a remarkably greater absolute increase than that of urban counterparts (urban: $\beta=0.035, P<0.001$, rural: $\beta=0.077, P<0.001)$. DMFT of rural children (0.54) got almost same level with their urban counterparts (0.54) in 2014. Meanwhile, DMFT of girls were higher than that of boys in all survey year and almost all subgroups $(P<0.001)$. The regional differences in DMFT were consistent with that in DMF\% $(P<0.001)$ (Table 3, Additional file 1: Table 1).

\section{The trend of CFR in overall and subgroups}

A continuously fluctuant trend of the CFR during 1995-2014 ( $Z=1.927, P>0.05)$ was observed, with a decrease from $17.4 \%$ in 1995 to $22.8 \%$ in 2000 and an increase to $23.4 \%$ in 2010 , then a decrease to $15.6 \%$ in 2014. CFR reached a bottom of $19.3 \%$ in 2005 and a summit of $23.4 \%$ in 2010 . CFR of urban children is considerably higher than that of rural counterparts at each survey year $(P<0.001)$. There was no significant

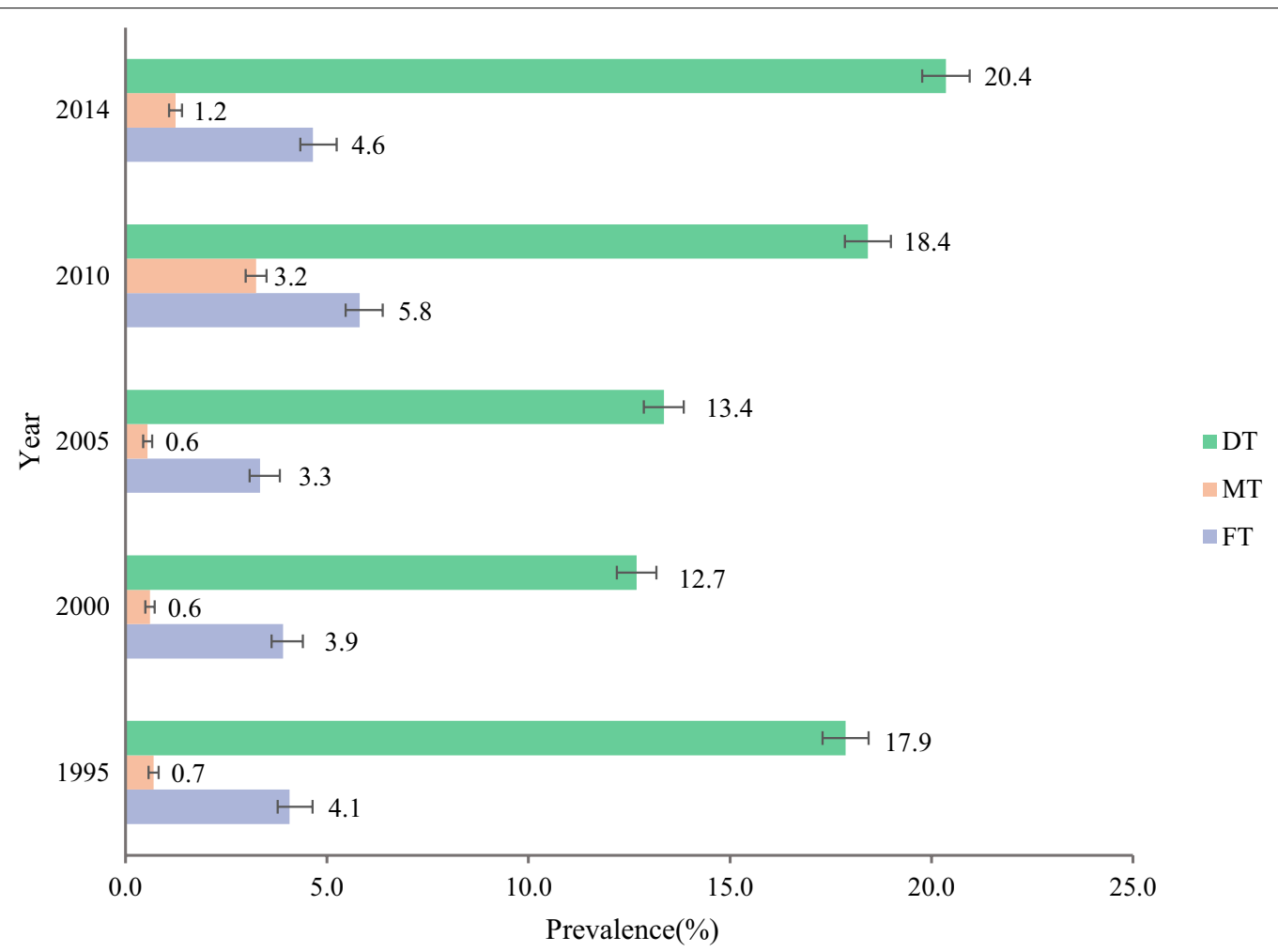

Fig. 1 Trend of DT\%, MT\%, FT\% in Chinese 12-year-old children from1995 to 2014. DT The percentage (\%) of the persons who had decayed in permanent teeth among all participants examined; MTThe percentage (\%) of the persons who had missing in permanent teeth among all participants examined; FT The percentage (\%) of the persons who had filled in permanent teeth among all participants examined 
Table 3 DMFT in 12-year-old Chinese children by gender (means, SD)

\begin{tabular}{|c|c|c|c|c|}
\hline & Overall & Boys & Girls & $t$-test $P$ value \\
\hline \multicolumn{5}{|l|}{1995} \\
\hline Total & $0.38(0.90)$ & $0.33(0.81)$ & $0.44(0.98)$ & $<0.001$ \\
\hline \multicolumn{5}{|l|}{ Area } \\
\hline Urban & $0.48(1.00)$ & $0.40(0.88)$ & $0.56(1.10)$ & $<0.001$ \\
\hline Rural & $0.29(0.78)$ & $0.25(0.73)$ & $0.32(0.83)$ & $<0.001$ \\
\hline \multicolumn{5}{|l|}{ Region } \\
\hline East & $0.52(1.05)$ & $0.43(0.92)$ & $0.62(1.17)$ & $<0.001$ \\
\hline Central & $0.30(0.80)$ & $0.26(0.75)$ & $0.35(0.84)$ & $<0.001$ \\
\hline West & $0.28(0.75)$ & $0.26(0.69)$ & $0.30(0.80)$ & 0.054 \\
\hline \multicolumn{5}{|l|}{2000} \\
\hline Total & $0.28(0.76)$ & $0.23(0.68)$ & $0.32(0.84)$ & $<0.001$ \\
\hline \multicolumn{5}{|l|}{ Area } \\
\hline Urban & $0.31(0.78)$ & $0.27(0.71)$ & $0.35(0.85)$ & $<0.001$ \\
\hline Rural & $0.25(0.75)$ & $0.20(0.64)$ & $0.30(0.83)$ & $<0.001$ \\
\hline \multicolumn{5}{|l|}{ Region } \\
\hline East & $0.42(0.95)$ & $0.35(0.84)$ & $0.49(1.04)$ & $<0.001$ \\
\hline Central & $0.14(0.49)$ & $0.13(0.47)$ & $0.15(0.51)$ & 0.137 \\
\hline West & $0.20(0.63)$ & $0.16(0.56)$ & $0.24(0.70)$ & $<0.001$ \\
\hline \multicolumn{5}{|l|}{2005} \\
\hline Total & $0.31(0.97)$ & $0.25(0.84)$ & $0.36(1.09)$ & $<0.001$ \\
\hline \multicolumn{5}{|l|}{ Area } \\
\hline Urban & $0.32(1.02)$ & $0.26(0.81)$ & $0.38(1.19)$ & $<0.001$ \\
\hline Rural & $0.29(0.92)$ & $0.25(0.86)$ & $0.34(0.98)$ & $<0.001$ \\
\hline \multicolumn{5}{|l|}{ Region } \\
\hline East & $0.39(1.15)$ & $0.31(0.96)$ & $0.47(1.32)$ & $<0.001$ \\
\hline Central & $0.26(0.93)$ & $0.23(0.84)$ & $0.28(1.00)$ & 0.040 \\
\hline West & $0.25(0.77)$ & $0.21(0.68)$ & $0.30(0.85)$ & $<0.001$ \\
\hline \multicolumn{5}{|l|}{2010} \\
\hline Total & $0.66(2.13)$ & $0.57(1.95)$ & $0.74(2.28)$ & $<0.001$ \\
\hline \multicolumn{5}{|l|}{ Area } \\
\hline Urban & $0.81(2.65)$ & $0.71(2.42)$ & $0.91(2.86)$ & $<0.001$ \\
\hline Rural & $0.50(1.40)$ & $0.44(1.32)$ & $0.57(1.48)$ & $<0.001$ \\
\hline \multicolumn{5}{|l|}{ Region } \\
\hline East & $0.42(1.03)$ & $0.32(0.92)$ & $0.51(1.11)$ & $<0.001$ \\
\hline Central & $0.39(0.99)$ & $0.34(0.88)$ & $0.44(1.08)$ & $<0.001$ \\
\hline West & 1.09 (3.20) & 0.99 (2.94) & $1.18(3.43)$ & 0.018 \\
\hline \multicolumn{5}{|l|}{2014} \\
\hline Total & $0.54(1.30)$ & $0.42(1.08)$ & $0.66(1.48)$ & $<0.001$ \\
\hline \multicolumn{5}{|l|}{ Area } \\
\hline Urban & $0.54(1.27)$ & $0.41(1.06)$ & $0.67(1.45)$ & $<0.001$ \\
\hline Rural & $0.54(1.33)$ & $0.43(1.10)$ & $0.66(1.51)$ & $<0.001$ \\
\hline \multicolumn{5}{|l|}{ Region } \\
\hline East & $0.69(1.50)$ & $0.54(1.27)$ & $0.84(1.69)$ & $<0.001$ \\
\hline Central & $0.46(1.19)$ & $0.35(0.96)$ & $0.57(1.37)$ & $<0.001$ \\
\hline West & $0.46(1.13)$ & $0.36(0.94)$ & $0.56(1.29)$ & $<0.001$ \\
\hline
\end{tabular}

difference between boys and girls at each survey year $(P>0.05)$ (Table 4, Additional file 1: Table 1).

\section{Discussion}

Globally, the prevalence of dental caries in 12-year-old children emerged a relatively fluctuant trend and showed controversial findings in various countries over the past 30 years. In Asian countries, DMFT had a decrease before 2006 and increase from 2006 to 2011 in Philippines, while in Japan, DMFT had a decreased yearly since 1975 [5]. In our study, we found that DMFT and DMF\% of 12-year-old Chinese children presented a V-shaped fluctuant upward trend over the past 20 years, with a decline trend from 1995 to 2000 and a significantly continuous upward trend from 2000 to 2014, and reached the lowest level in 2000. Although compared with the results of European countries and the world [4, 20], both DMFT and DMF\% were at relative low levels, the rising trend reminds us that the situation of caries in China is still not optimistic and faces great challenges.

From 1995 to 2000, the prevalence of dental caries in permanent teeth in 12-year-old Chinese children showed a decreasing trend, which may be related to the three oral health care strategies adopted in China during this period: (1) public oral health education; (2) pit and fissure sealing services; (3) fluoridation [21]. Regarding public oral health education, the ministry of education promulgated and stipulated a series of policies to promote oral health from the mid-1990s to the early 2000s [22, 23]. However, there was much less from 2000 to 2014. Moreover, the study found that after the reform of the basic education curriculum in 2001, school health education on dental caries was not well implemented, which may make it difficult to guarantee the timing and content of oral health education for children [24]. As for pit and fissure sealing service, China began to promote it nationally to prevent children's dental caries in 1993 [25]. Dental sealant programs had been found to prevent up to $80 \%$ of tooth decay in the treated teeth [26]. Regarding using fluoride to prevent caries, nationwide pilot projects began to be carried out for fluoridated drinking water, salt, milk and toothpaste since 1991 [27]. Clinical trials have shown that fluoride can significantly reduce tooth decay [28]. However, due to safety concerns, the use of fluoride was not promoted after the end of the project, even though cariogenic foods and beverages were rapidly developed at the same time. Fluorinated toothpaste had been promoted and available nationwide since 1989, even though surveys show that its use is not popular [29]. 


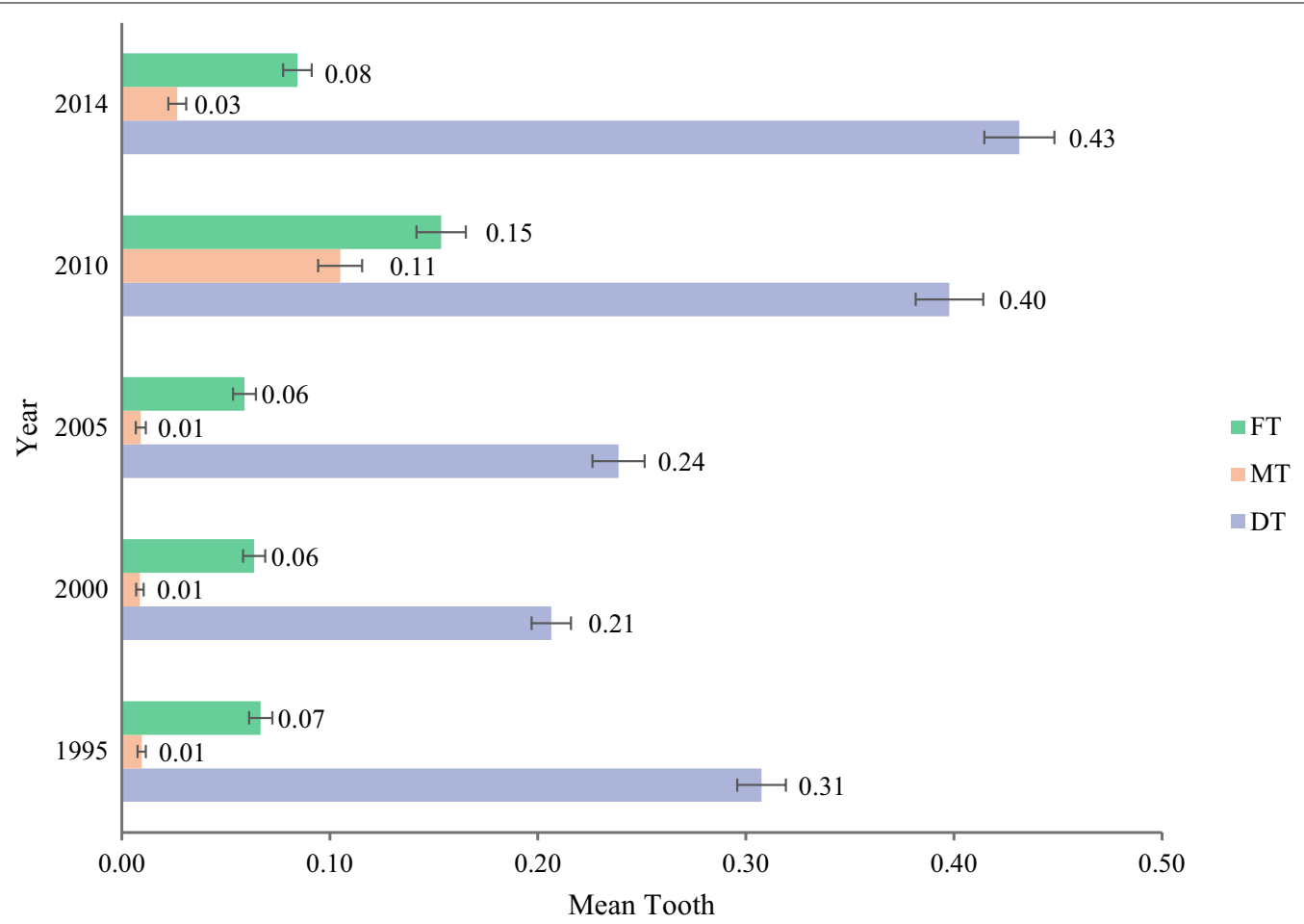

Fig. 2 Trend of DT, MT, FT in Chinese 12-year-old children from1995 to 2014. DT The mean number of decayed teeth among all participants examined; MTThe mean number of missing teeth among all participants examined; FTThe mean number of filled teeth among all participants examined

From 2000 to 2014, the prevalence of dental caries in permanent teeth in 12-year-old Chinese children showed a significantly continuous upward trend, which may be related to changes in people's dietary patterns and the rapid development of caries-causing foods and drinks, as well as the relative weakness of dental caries prevention and services. With the socioeconomic development [30], food choices became more diverse and the public consumption patterns shifted from high-fiber, lowsugar diets to high-sugar, high-energy diets, especially among children. Studies have shown a positive association between amount of free sugars consumption and dental caries experiences [31]. In China, per capita sugar production was continually increasing from 76.35 million tons in 2000 to 120.8 million tons in 2014, and added sugar food consumption was continually increasing from $8.2 \%$ in 2000 to $25.4 \%$ in 2009 [12].

Our study found the difference between urban and rural children, as well as the changing of the difference. DMF\% and DMFT of 12-year-old Chinese children in urban group were higher than their rural counterparts from 1995 to 2010. However, over time, the gap between urban and rural areas gradually narrowed, and by 2014, the DMFT of rural children was even in line with that of urban children. One reason may be a convergence of urban and rural lifestyles has been occurring in China as urbanization advanced, resulting in an increase in caries-related unhealthy lifestyles among rural children [32], such as a growing obesity epidemic [33]. Besides, unequal distribution of oral health professionals and lack of appropriate health facilities mean that access to oral health services in rural areas is limited. As a result, rural children are becoming more vulnerable and should be taken seriously.

Also, our study found the difference between boys and girls. DMF\% and DMFT in girls were higher than boys at all survey years. This result is consistent with a widely documented argument that girls have presented with a higher prevalence of dental caries than boys throughout time and across cultures [34, 35]. The reason is usually explained by the following three factors: (1) Earlier eruption of teeth in girls, hence longer exposure of girls' teeth to the cariogenic oral environment [35]; (2) Girls prefer carbohydrates and sugary foods [36], which may lead to more dental caries experiences [35, 37]; (3) Physiological studies found that women's average salivary flow rate was significantly lower than men's due to the effects of estrogen and saliva flow is the medium that brings protective agents into the oral cavity [38-40]. 
Table 4 CFR in 12-year-old Chinese children by gender (\%, $95 \% \mathrm{Cl})$

\begin{tabular}{|c|c|c|c|c|}
\hline & Overall & Boys & Girls & $\begin{array}{l}\text { Chi-square- } \\
\text { test } P \text { value }\end{array}$ \\
\hline \multicolumn{5}{|l|}{1995} \\
\hline Total & $17.4(16.5-18.3)$ & $17.1(15.8-18.5)$ & $17.6(16.4-18.8)$ & 0.641 \\
\hline \multicolumn{5}{|l|}{ Area } \\
\hline Urban & $23.8(22.5-25.0)$ & $23.8(21.8-25.8)$ & $23.8(22.1-25.4)$ & 0.983 \\
\hline Rural & $6.4(5.5-7.4)$ & $6.5(5.1-8.0)$ & $6.3(5.0-7.7)$ & 0.848 \\
\hline \multicolumn{5}{|l|}{ Region } \\
\hline East & $23.4(22.0-24.8)$ & $23.5(21.3-25.7)$ & $23.4(21.6-25.2)$ & 0.920 \\
\hline $\begin{array}{l}\text { Cen- } \\
\text { tral }\end{array}$ & $10.4(8.9-11.9)$ & $10.8(8.5-13.2)$ & $10.1(8.1-12.1)$ & 0.651 \\
\hline West & $10.6(9.0-12.1)$ & $10.3(8.1-12.5)$ & $10.8(8.6-12.9)$ & 0.758 \\
\hline \multicolumn{5}{|l|}{2000} \\
\hline Total & $22.8(21.7-24.0)$ & $22.1(20.3-23.9)$ & $23.3(21.8-24.9)$ & 0.333 \\
\hline \multicolumn{5}{|l|}{ Area } \\
\hline Urban & $33.3(31.5-35.1)$ & $32.1(29.4-34.8)$ & $34.2(31.8-36.6)$ & 0.247 \\
\hline Rural & $9.7(8.5-11.0)$ & $8.4(6.6-10.3)$ & $10.5(8.9-12.2)$ & 0.107 \\
\hline \multicolumn{5}{|l|}{ Region } \\
\hline East & $26.0(24.5-27.6)$ & $25.4(23.0-27.8)$ & $26.5(24.5-28.5)$ & 0.507 \\
\hline $\begin{array}{l}\text { Cen- } \\
\text { tral }\end{array}$ & $17.8(14.9-20.8)$ & $18.4(14.0-22.8)$ & $17.4(13.4-21.3)$ & 0.736 \\
\hline West & $16.8(14.6-18.9)$ & $15.7(12.4-19.0)$ & $17.5(14.6-20.4)$ & 0.410 \\
\hline \multicolumn{5}{|l|}{2005} \\
\hline Total & $19.3(18.3-20.4)$ & $20.2(18.5-21.8)$ & $18.7(17.4-20.1)$ & 0.176 \\
\hline \multicolumn{5}{|l|}{ Area } \\
\hline Urban & $25.6(24.0-27.2)$ & $25.8(23.3-28.3)$ & $25.4(23.4-27.5)$ & 0.796 \\
\hline Rural & $12.4(11.2-13.7)$ & $14.2(12.1-16.3)$ & $11.2(9.6-12.7)$ & 0.020 \\
\hline \multicolumn{5}{|l|}{ Region } \\
\hline East & $26.8(25.1-28.5)$ & $28.5(25.8-31.2)$ & $25.7(23.5-27.8)$ & 0.103 \\
\hline $\begin{array}{l}\text { Cen- } \\
\text { tral }\end{array}$ & $11.9(10.0-13.8)$ & $10.4(7.7-13.1)$ & $13.0(10.4-15.6)$ & 0.179 \\
\hline West & $12.5(10.9-14.1)$ & $14.2(11.7-16.8)$ & $11.2(9.3-13.2)$ & 0.064 \\
\hline \multicolumn{5}{|l|}{2010} \\
\hline Total & $23.4(22.6-24.2)$ & $23.8(22.6-24.9)$ & $23.1(22.1-24.1)$ & 0.677 \\
\hline \multicolumn{5}{|l|}{ Area } \\
\hline Urban & $27.8(26.8-28.9)$ & $28.5(26.9-30.1)$ & $27.3(26.0-28.7)$ & 0.278 \\
\hline Rural & $16.3(15.2-17.3)$ & $16.1(14.4-17.7)$ & $16.4(15.0-17.8)$ & 0.767 \\
\hline \multicolumn{5}{|l|}{ Region } \\
\hline East & $26.9(25.2-28.5)$ & $28.9(26.2-31.6)$ & $25.6(23.5-27.7)$ & 0.060 \\
\hline $\begin{array}{l}\text { Cen- } \\
\text { tral }\end{array}$ & $10.6(9.2-12.0)$ & $10.0(7.9-12.1)$ & $11.0(9.1-12.9)$ & 0.494 \\
\hline West & $25.4(24.4-26.4)$ & $25.5(24.0-27.0)$ & $25.3(23.9-26.6)$ & 0.854 \\
\hline \multicolumn{5}{|l|}{2014} \\
\hline Total & $15.6(14.9-16.3)$ & $14.9(13.8-16.1)$ & $16.0(15.1-16.9)$ & 0.161 \\
\hline \multicolumn{5}{|l|}{ Area } \\
\hline Urban & $18.7(17.6-19.8)$ & $18.7(16.9-20.5)$ & $18.7(17.3-20.1)$ & 0.998 \\
\hline Rural & $12.5(11.5-13.4)$ & $11.3(9.9-12.7)$ & $13.2(12.0-14.5)$ & 0.043 \\
\hline \multicolumn{5}{|l|}{ Region } \\
\hline East & $23.1(21.8-24.3)$ & $22.4(20.4-24.3)$ & $23.5(21.9-25.1)$ & 0.377 \\
\hline $\begin{array}{l}\text { Cen- } \\
\text { tral }\end{array}$ & $11.2(9.8-12.5)$ & $12.3(10.1-14.6)$ & $10.4(8.8-12.1)$ & 0.172 \\
\hline West & $7.3(6.3-8.2)$ & $5.5(4.1-6.8)$ & $8.5(7.2-9.8)$ & 0.002 \\
\hline
\end{tabular}

In terms of attendance to oral health services, we found that CFR levels of 12-year-old Chinese children from 1995 to 2014 were low and there was no gender difference, which is consistent with the results of the Fourth National Survey of Children's Oral Health of China (15.6\%) [29]. In Japan, $22.79 \%$ of students completing dental treatment in 2014 [41]. In New Zealand and Australia, the CFR even reached 90\% [42]. This suggests that there is still a big gap in the treatment of children caries in China. It is unclear whether there is a gender difference in oral health service utilization and may be worth further study.

\section{Strengths and limitations}

Our study has several strengths. First, the sample population is the largest and the best nationally representative student survey sample in China. Second, our study comprehensively assessed the development trends of dental caries in permanent teeth in 12-year-old Chinese children from 1995 to 2014, as well as the differences between urban-rural areas, boys and girls. These results commendably complement the research report and provide valuable reference for policy making in China and other middle-income countries. Meanwhile, our study also has several limitations that should be noted. First, we did not used lightweight portable examination light (in the blue-white color spectrum) used internationally to examine caries, and the dental caries examination was not performed in the dental chair, which may underestimate the prevalence of caries. However, the bias is within the acceptable range and studies using the same approach have been published in journals [43]. Therefore, the results across the five consecutive national surveys still comparable and can reflect the trend of caries in Chinese children. Second, we did not perform the calibration process for DMFT, and the inter-and intra-examiner Kappa statistics for DMFT. Although the use of different measurement instruments and different examiners could affect the consistency of the examination, they should not affect the assessment of trends of dental caries in permanent teeth over time, especially in the five survey cycles. The principles underlying the methods are the same ones and the quality control meets the requirements.

\section{Conclusions}

In conclusion, our study found that, over the past 20 years, DMFT and DMF\% of 12-year-old Chinese children presented V-shaped fluctuant upward trends with a decline trend from 1995 to 2000 and a significantly continuous upward trend from 2000 to 2014, and reached 
the lowest level in 2000. Meanwhile, caries filling situation had no significant improvement. The rural children and girls are the more vulnerable groups in the development of dental caries and need to pay priority. Our study supports the continuation of policies to improve students' oral health.

\section{Abbreviations}

DMF\%: Prevalence of decayed, missing and filled teeth; DMFT: Mean decayed, missing, filled teeth score; CFR: Caries filling ratio; NCD: Non-communicable diseases; WHO: World Health Organization; CNSSCH: Chinese National Survey on Students' Constitution and Health; DT: Decayed tooth; MT: Missing tooth; FT: Filled tooth; SPSS: Statistical Package for the Social Sciences.

\section{Supplementary Information}

The online version contains supplementary material available at https://doi. org/10.1186/s12903-021-01814-7.

Additional file 1: Table 1. Secular changes of DMF\%, DMFT and CFRamong 12-year-old Chinese children from 1995 to 2014.

Additional file 2: Table 2. The classification of DMF\% and DMFT in 12-year-old Chinese children from 1995-2014 (\%, 95\%Cl).

\section{Acknowledgements}

We would like to thank all members, children, schools and families, of all these consecutive surveys for their collaboration and all the people involved in data collection and processing.

\section{Authors' contributions}

Z.H. contributed to the data curation, data analysis and interpretation and was a major contributor in writing the manuscript. X.Y.: contributed to the sorting and analysis of data. Y.S.: contributed to the supervision, methodology, resources, review, project administration, data curation and editing of the manuscript. S.M.: contributed to editing of the manuscript. J.M.: contributed to the supervision, methodology, resources, project administration, data curation, review. G.Z.: lead the research team, proposed the idea, designed the study and edited the manuscript. All authors read and approved the final manuscript.

\section{Funding}

This study was funded by the National Natural Science Foundation of China (Grant Number 81673192), China. These funding sources had no role in the design of this study and did not have any role during its execution, analyses, interpretation of the data, or decision to submit results.

\section{Availability of data and materials}

The datasets used and/or analyzed during the current study are not publicly available but are available from the corresponding author on reasonable request.

\section{Declarations}

\section{Ethics approval and consent to participate}

The project was approved by the Medical Research Ethics Committee of Peking University Health Science Center (IRB00001052-18002). All participants in the study were 12 years old. With data collected from schools across China, the school principals determined the process for gaining informed parental consent (i.e., written vs. verbal, active vs. passive); informed consent was obtained from both children and their parents. The procedures of CNSSCH have been published previously and kept uniform during the 20-year period [29].

\section{Consent for publication}

Not applicable.

\section{Competing interests}

The authors declare that they have no competing interests.

\section{Author details}

${ }^{1}$ Institute of Child and Adolescent Health, School of Public Health, Peking University, No. 38 Xueyuan Rd, Haidian District, Beijing 100191, China. ${ }^{2}$ Division of Prevention and Community Health, National Center for Cardiovascular Disease, Fuwai Hospital, Peking Union Medical College \& Chinese Academy of Medical Sciences, Mentougou District, Beijing, China. ${ }^{3}$ Institute of Population Research, Peking University, Beijing, China. ${ }^{4}$ School of Health Humanities, Peking University, Beijing, China.

Received: 2 June 2020 Accepted: 8 September 2021

Published online: 23 September 2021

\section{References}

1. World Health Organization. Sugars and dental caries. World Health Organization, 2017.

2. World Health Organization. Oral health indicators for 2000. Dental caries at 12 years.850503, 0373V/000A. WHO Geneva.

3. Yang ML, Lou XM, Li L, et al. Prevalence of dental caries among primary and middle school students in Henan province from 1991 to 2010. J Zhengzhou Univ (Med Edn). 2013;48(02):245-8.

4. WHO Oral Health Programme. (2000). Global data on dental caries prevalence (DMFT) in children aged 12 years / Global Oral Data Bank, Oral Health/Area Profile Programme. World Health Organization. Available from: https://apps.who.int/iris/handle/10665/66520. Accessed 2000.5.20.

5. WHO collaborating center for education, training and research in oral health. Global DMFT for 12-year-olds: 2011. Available from: http://www. mah.se/CAPP/Country-Oral-Health-Profiles/According-to-Alphabetical/ Global-DMFT-for-12-year-olds-2011/. Accessed 2019.10.21

6. Tang J, Yu Y, et al. The epidemic tendency of dental caries prevalence of school students from 1991 to 2005 in China. J Huazhong Univ Sci Technol Med Sci. 2010.

7. Dobbiani A, Berton F, Perinetti $G$, et al. Prevalence of dental caries among schoolchildren from North-Eastern Italian population. Minerva Stomatol. 2018:67(2):49-54.

8. David J, Wang NJ, Åstrøm AN, et al. Dental caries and associated factors in 12-year-old schoolchildren in Thiruvananthapuram, Kerala, India. Int J Pediatr Dent. 2005;15(6):420-8.

9. Kalita C, Choudhary B, Saikia AK, et al. Caries prevalence of school-going boys and girls according to cleaning methods and soft drink-taking frequency in different localities, in and around Guwahati City. J Indian Soc Pedodont Prev Dent. 2016:34(3):249.

10. Maharani DA, Zhang S, Gao SS, et al. Dental caries and the erosive tooth wear status of 12-year-old children in Jakarta, Indonesia. Int J Environ Res Public Health. 2019;16(16):2994.

11. Sun YH. Poor eating, insufficient sleep, and little activity: there are several hidden dangers of healthy life for children-based on the large sample survey and longitudinal comparative analysis of more than 6000 primary and secondary school students in China. Manag Prim Second Schools, 2018, No.327(02):47-50.

12. National Bureau of Statistics of China. sugar production per capita. Available from: http://data.stats.gov.cn/easyquery.htm? $\mathrm{cn}=\mathrm{C} 01 \& \mathrm{zb}=\mathrm{AODOR} \&$ $s j=2019$. Accessed 2019.11 .6

13. Liu S. The consumption status and change of sugar containing food and its relationship with overweight and obesity in China from 2002 to 2012. Chinese Center for Disease Control and Prevention, 2016.

14. Ji CY, Cheng TO. Prevalence and geographic distribution of childhood obesity in China in 2005. Int J Cardiol. 2008;131(1):1-8.

15. Ma J, Wang Z, Song Y, et al. BMI percentile curves for Chinese children aged 7-18 years, in comparison with the WHO and the US Centers for Disease Control and Prevention references. Public Health Nutr. 2010;13(12):1990-6

16. Song $\mathrm{Y}$, Wang $\mathrm{H} \mathrm{J}$, Dong $\mathrm{B}$, et al. 25 -year trends in gender disparity for obesity and overweight by using WHO and IOTF definitions among Chinese school-aged children: a multiple cross-sectional study. BMJ open, 2016, 6(9): e011904. 
17. National Bureau of Statistics of China. East, west, central and east-northeast division methods in China. http://www.stats.gov.cn/ztjc/zthd/sjtjr/ dejtjkfr/tjkp/201106/t20110613_71947.htm (Accessed 13 Jun 2011).

18. CNSSCH Association. Report on the 2014th National Survey on Students' Constitution and Health. Beijing: China College \& University Press; 2016. (in Chinese).

19. World Health Organisation. Oral Health Surveys. Basic Methods. 3rd ed. Geneva:WHO, 1987.

20. Maldupa I, Sopule A, Uribe S E, et al. Caries prevalence and severity for 12-year-old children in Latvia. International Dental Journal. 2020.

21. Morris AJ, Nuttall NM, White DA, et al. Patterns of care and service use amongst children in the UK 2003. Br Dent J. 2006;200(8):429-34.

22. MEPRC (1990) Regulations on school health work. http://www.moe. gov.cn/srcsite/A02/s5911/moe_621/201511/t20151119_220046.html. Accessed 29 October 2019.

23. MHPRC, SECPRC, NPPHCC (1993) Basic requirements of health education for primary and secondary school students (trial). Health education in China (07): 9-12

24. Zhu GR, Yu XM, Shi XY. Curriculum standard analysis of courses relating to health education. Chinese preventive medicine association/Children's hygiene club/National academic exchange conference. 2008.

25. Huang SH. Principles and methods of using pit and fissure sealant. Prev Treat Oral Dis. 1993;2:55-9.

26. Oral Health. Available from: https://www.healthypeople.gov/2020/topicsobjectives/topic/oral-health. Accessed 2010.10.29.

27. Zhang BX, Lin YN, Wang SN. Decade of prevention and treatment of dental diseases in China. Beijing. Beijing Medical University Press 1999: 24-30.

28. Rong WS, Bian JY, Wang WJ, et al. Effectiveness of an oral health education and caries prevention program in kindergartens in China. Commun Dent Oral Epidemiol. 2003, 31(6).

29. The results of Chinese fourth oral health epidemiological survey were released. Available from: http://www.gov.cn/xinwen/2017-09/20/conte nt_5226224.htm. Accessed 2010.9.20.

30. Notice on accelerating reform of the grain circulation system issued by the State Council. 15 February 1993. Available from: https://www. scio.gov.cn/zhzc/6/2/Document/1003284/1003284.htm. Accessed 2019.10.29.

31. Olczak-Kowalczyk D, Turska A, Gozdowski D, et al. Dental caries level and sugar consumption in 12-year-old children from Poland. Adv Clin Exp Med. 2016;25(3):545-50.
32. Dong Y, Lau PW C, Dong B, et al. Trends in physical fitness, growth, and nutritional status of Chinese children and adolescents: a retrospective analysis of 15 million students from six successive national surveys between 1985 and 2014. Lancet Child Adolesc Health, 2019, 3(12): $871-880$

33. Yao $Y$, Ren $X$, Song $X$, et al. The relationship between dental caries and obesity among primary school children aged 5 to 14 years. Nutr Hosp. 2014;30(n01):60-5.

34. Lukacs JR. Sex differences in dental caries experience: clinical evidence, complex etiology. Clin Oral Investig. 2011;15(5):649-56.

35. Lukacs JR, Largaespada LL. Explaining sex differences in dental caries prevalence: Saliva, hormones, and "life-history" etiologies. Am J Hum Biol. 2006;18(4):540-55.

36. Drewnowski A, Kurth C, Holden-Wiltse J, et al. Food preferences in human obesity: carbohydrates versus fats. Appetite. 1992;18(3):207-21.

37. Grogan SC, Bell R, Conner M. Eating sweet snacks: gender differences in attitudes and behaviour. Appetite. 1997;28(1):19-31.

38. Suo SM, Zhao XP. Investigation and analysis of dental caries in college students in Shanxi Province. J Changzhi Med College. 2005;19(1):9-11.

39. Percival RS, Challacombe JS, et al. Flow rates of resting whole and stimulated parotid saliva in relation to age and gender. J Dent Res. 1994.

40. Leimola-Virtanen R, Salo T, Toikkanen S, et al. Expression of estrogen receptor (ER) in oral mucosa and salivary glands. Maturitas. 2000:36(2):131-7.

41. Statistics of Japan. School health statistics survey 2014- by age/installer Disease/abnormal incidence rate, etc. Available from: https://www.e-stat go.jp/dbview?sid=0003107431. Accessed 2019.10.29.

42. Japan School Health Association. school health of the trend (Heisei 15 fiscal year). Japan School Health Association, 2003.

43. Xu L, Wan YH, Zhang H, et al. Comparison of caries incidence of primary and secondary school students in urban and rural areas in Anhui province from 2005 to 2014. Chin J School Health. 2016;6:885-7.

\section{Publisher's Note}

Springer Nature remains neutral with regard to jurisdictional claims in published maps and institutional affiliations.
Ready to submit your research? Choose BMC and benefit from:

- fast, convenient online submission

- thorough peer review by experienced researchers in your field

- rapid publication on acceptance

- support for research data, including large and complex data types

- gold Open Access which fosters wider collaboration and increased citations

- maximum visibility for your research: over $100 \mathrm{M}$ website views per year

At BMC, research is always in progress.

Learn more biomedcentral.com/submissions 